\title{
Patient Safety in Delayed Diagnosis of Acute Appendicitis
}

\author{
Aly Saber ${ }^{1}$, Mohammad A. Gad ${ }^{2}$, Goda M. Ellabban ${ }^{2}$ \\ ${ }^{1}$ Department of General Surgery, Port-Fouad General Hospital, Port-Fouad, Egypt \\ ${ }^{2}$ Department of Surgery, Faculty of medicine, Suez Canal University, Ismailia, Egypt \\ E-mail: Alysaber54@gmail.com \\ Received January 11, 2011; revised March 24, 2011; accepted July 21, 2011
}

\begin{abstract}
Introduction: acute appendicitis is the major surgical abdominal disease in emergency departments and is also among the five leading causes of litigation against emergency physicians. Delayed diagnosis of appendicitis is more likely to occur in patients, who present atypically, and those lack a thorough physical examination, or those received intramuscular narcotic analgesia. The aim of this study was to study the effect of delay in diagnosis of acute appendicitis as regard postoperative findings, length of hospital stay and postoperative complications. Patients \& Methods: patients with complicated appendicitis were subjected to the present study and treated by a single surgical team. The parameters of our study were incidence of perforation or gangrene at surgery, length of stay and post-operative complications. Results: the present study showed that delay in diagnosis of acute appendicitis is associated with a more advanced stage of disease and a higher morbidity. Conclusion: careful attention to the patient's history; a thorough physical examination and early clinical review help to minimize the possibility of delayed diagnosis of appendicitis. Appendicitis with a delay in treatment usually leads to high perforation rates, and unfavorable outcome.
\end{abstract}

Keywords: Acute Appendicitis, Delayed Diagnosis, Patient Safety

\section{Introduction}

Acute appendicitis is the major surgical abdominal disease in emergency departments [1] and it is also among the five leading causes of litigation against emergency physicians. The vast majority of causes of the claims against physicians were clustered around "diagnosis error", accounting for about one-third of the claims [2].

Appendicitis is more common for negligent adverse events in claim data as it was 25 times more likely to generate a claim for negligence than breast cancer $[2,3]$. The error rate in diagnosing patients with pain in the right iliac fossa approaches $40 \%$, and the appendix is normal in approximately $20 \%$ of patients who undergo exploratory laparotomy because of suspected appendicitis [2].

It is still difficult to make a correct preoperative diagnosis early enough that patients can avoid unnecessary appendectomies and reduce the risk of perforation. This is because the initial symptoms of early appendicitis are nonspecific and may often confuse treating physicians. In addition, attempts at seeking a correct diagnosis and avoiding unnecessary appendectomies may actually cause the delay of surgery and increase the possibility of perforation and morbidity [4].

A delay in diagnosis of appendicitis is more likely to occur in patients, who present atypically, with fewer complaints of right lower quadrant pain and those lack a thorough physical examination, or those received intramuscular narcotic analgesia [5]. Diagnostic aids can dramatically reduce negative appedecectomies, perforations and hospital stay. These aids are laparoscopy, scoring systems, ultrasonography and computed tomography [6].

\section{Aim of the Work}

The aim of this study was to study the effect of delay in diagnosis of acute appendicitis as regard postoperative findings, length of hospital stay and post-operative complications.

\section{Patients \& Methods}

\subsection{Study Site \& Population}

Information collected from database in Port Fouad gen- 
eral hospital between January 1, 2006 and March 1, 2008. All patients, male and females at any age, admitted during that period for surgery for complicated appedecectomy were subjected to the present study and treated by a single surgical team consisted of a consultant surgeon, general surgeon and two residents.

\subsection{Collected Data}

Data were collected from the registration and statistics unit in Port Fouad general hospital within the abovementioned period. Data included all cases of complicated appedecectomies subjected to surgery by the same single surgical team.

Parameters of evaluation:

1) Incidence of perforation or gangrene at surgery,

2) Length of stay (LOS), and

3) post-operative complications.

The operative finding was graded as four-grade system Grade 1 (G I) for acute appendicitis, Grade 2 (G II) for gangrenous acute appendicitis, Grade 3 (G III) for perforation, and Grade 4 (G IV) for a periappendicular abscess [7].

Definition of delayed diagnosis:

Delayed diagnosis was considered as:

a) discharge from the emergency room department (ED) at the first visit or,

b) a time from initial examination to surgery of 20 hours or more [8].

\subsection{Statistical Analysis}

Gathered data was analyzed using the Statistical Package for Social Sciences 15 (SPSS Inc., Chicago, IL, USA) and MedCalc version 9.2. Qualitative data was expressed as numbers and percentages while quantitative data was expressed as mean \pm standard deviations (SD). Chi square was used to test significance of the difference between qualitative data and Student $t$ test was used to test significance of the difference between quantitative data. Probability value ( $\mathrm{p}$-value) $<0.05$ was considered statistically significant.

\section{Results}

The overall number of appedecectomies done within the period of study was 112 by the same single surgical team. The total number of complicated appedecectomy was 22 patients, 16 males and 6 females. Perforated appendicitis was seen in 6 and gangrenous appendicitis in 14 patients and 2 cases showed evidences of periappendicular abscess (Table 1).

The pattern of delayed diagnosis was discharge from
Table 1. Distribution of complications among complicated cases.

\begin{tabular}{cccc}
\hline Complication & Grade & Number & $\%$ \\
\hline Gangrenous & II & 14 & $63.6 \%$ \\
Perforated & III & 6 & $27.3 \%$ \\
Periappendicular abscess. & IV & 2 & $9.1 \%$ \\
\hline
\end{tabular}

the emergency room department in 21 patients and in only one patient, the delay was due to reluctant administrative attitude.

The length of hospital stay was studied in patients treated for simple non-complicated appendicitis and those with complicated appendicitis (Table 2). Post-operative complications were monitored and addressed as: prolonged ileus, wound sepsis and intra-abdominal sepsis.

Postoperative bowel function was studied in both groups. In non-complicated appendicitis patients, the bowel motions were regained as early as $8-12$ hours while in those with complicated appendicitis ileus was apparent as mild abdominal distension and delayed restoration of gut movement up to 36 - 72 hours (Table 3).

Septic complications were detected in both groups. The incidence was greater in complicated than noncomplicated appendicitis patients as well as the pattern of sepsis was different in both groups. In non-complicated appendicitis patients, no intra-abdominal sepsis was detected while in complicated appendicitis patients, intra-abdominal sepsis was detected as pelvic abscess in $2 / 22$ patients and deep wound sepsis was seen in $6 / 22$ patients (Table 4).

\section{Role of Surgical and Non-surgical Residents}

The role of surgical and non-surgical residents in delayed diagnosis of patients with acute appendicitis was traced. We reviewed the patients files, subjected to the present study, regarding the full history, clinical examination, vital signs recording by both surgical and non-surgical residents.

\section{Discussion}

Acute appendicitis is the second most common cause of surgical abdominal disease in late adulthood and major errors in management are made frequently and the condition is associated with significant morbidity and mortality [9].

A perceived high rate of complicated, gangrenous or perforated, appendicitis, despite advances in laboratory and radiographic diagnostic modalities, prompted a review of cases of appendicitis as regard the time course from presentation to definitive treatment. The high rate 
Table 2. Length of hospital stay in simple and complicated cases.

\begin{tabular}{cccc}
\hline Types & Minimum & Maximum & Mean \pm SD \\
\hline Simple $(n=90)$ & $24 \mathrm{hr}$ & $48 \mathrm{hr}$ & $36.29 \pm 8.5 \mathrm{hr}$ \\
Complicated $(n=22)$ & $96 \mathrm{hr}$ & $168 \mathrm{hr}$ & $126.31 \pm 34.1 \mathrm{hr}$ \\
& t-test & & 22.6 \\
p-value & & $0.00^{*}$ \\
\hline
\end{tabular}

*Statistically significant difference.

Table 3. Time in hours elapsed till regain of bowel motions.

\begin{tabular}{cccc}
\hline Group & Minimum & Maximum & Mean $\pm \mathrm{SD}$ \\
\hline non-complicated & $8 \mathrm{hr}$ & $12 \mathrm{hr}$ & $10.12 \pm 1.45 \mathrm{hr}$ \\
Complicated & $36 \mathrm{hr}$ & $72 \mathrm{hr}$ & $54.61 \pm 15.31 \mathrm{hr}$ \\
& t- test & & 27.45 \\
& p-value & & $0.00^{*}$ \\
\hline
\end{tabular}

"Statistically significant difference.

Table 4. Incidence of septic complications among complicated and non-complicated cases.

\begin{tabular}{ccccc}
\hline Group & & $\begin{array}{c}\text { Non-complicated } \\
(n=90)\end{array}$ & $\begin{array}{c}\text { Complicated } \\
(n=22)\end{array}$ & p-value \\
\hline Wound sepsis & $\mathrm{N}(\%)$ & $2(2.2 \%)$ & $6(27.3 \%)$ & $0.003^{*}$ \\
$\begin{array}{c}\text { intra-abdominal } \\
\text { sepsis }\end{array}$ & $\mathrm{N}(\%)$ & $0(0 \%)$ & $2(9.1 \%)$ & $0.04^{*}$ \\
\hline
\end{tabular}

"Statistically significant difference.

of complicated appendicitis with its subsequent sequelae of increased morbidity is primarily the direct result of patient delay [10].

In the present study, we showed that delay in diagnosis of acute appendicitis was associated with a more advanced stage of disease and a higher morbidity. Other study stressed on the pre-admission delay on the part of the patient and the post-admission delay on the part of the surgeon as how both shared in causing a more advanced stage of disease and consequent complications is still debated $[6,9,10]$.

Although acute appendicitis is among the five leading causes of litigation against emergency physicians $[10,11]$, we could not find such files in our local legal medicine department despite the significant level of delayed diagnosis of patients with appendicitis. Because of the initial symptoms of early appendicitis are nonspecific, a correct preoperative diagnosis early enough is mandatory to avoid unnecessary appendectomies and reduce the risk of perforation $[11,12]$. We think that it is the role of treating physicians to seek a correct diagnosis and avoid unnecessary appendectomies, the delay of surgery and increase the possibility of perforation and morbidity.

Our data came in agreement with those studies of same interest as all suggested that delay may, however, result in an increase in cost, especially for those patients in whom the emergency room-operative room period extends beyond 12 hours, or in an increase in long hospital stay in those in whom admit-operative room duration is greater than six hours [11-13].

Regarding the role of surgical and non-surgical residents in delayed diagnosis of patients with acute appendicitis, we found that training background of residents affected their diagnosis of acute appendicitis in the emergency department as stated in other study of same interest 4 . The surgical residents were well-oriented to the clinical data and their diagnosis was based primarily on the patient's history and the physical examination. While the non-surgical residents depended on the laboratory test and ultrasonography as complimentary aids to the clinical data.

Some studies showed that the diagnosis of acute appendicitis relies largely on clinical experience and the performance of complementary tests is oftentimes unnecessary $[14,15]$. Others reported that radiological examinations are very helpful to determine the diagnosis even when the patient presents atypically [16]. The Alvarado score is a validated test in clinical adult surgery practice which can be helpful in the diagnosis of acute appendicitis [4,6,17] but not in female patients [18].

Due to the fact that no single score may be used alone to dictate or decline surgery and different cut-off points may also be considered for different subpopulations [19]. It is well known that precaution appendectomy or misdiagnosis of presumed appendicitis is an adverse outcome that leads to unnecessary surgery, serious interruption of patient's daily activities and considerable waste of hospital resources [20]. Here, the authors stressed on the higher index of suspicion, better surgical training, and better senior supervision at the emergency departments, to avoid preventable morbidity and mortality in acute appendicitis [21].

\section{Conclusions}

Diagnosis of acute appendicitis may be a difficult task and remains a clinical challenge in the emergency departments. Despite technologic advances, the diagnosis of appendicitis is still based primarily on the patient's history and the physical examination.

Careful attention to the patient's history, a thorough physical examination and early clinical review will minimize the possibility of a delay in diagnosis of appendicitis. Appendicitis with a delay in treatment usually leads to high perforation rates, and unfavorable outcome 
parameters. The problem of late presentation and/or referral should be addressed, perhaps by education of primary care physicians and the public. Public education, specifically targeting those groups at risk, may provide a substantial and significant solution to the complicated appendix.

\section{Acknowledgements}

The authors would appreciate the efforts of Mrs. Mervat Kamel for her help in writing, preparing tables and editing the manuscript.

\section{References}

[1] C. Clyde, T. Bax, A. Merg, M. MacFarlane, P. Lin, S. Beyersdorf and M. S. McNevin, "Timing of Intervention does Not Affect Outcome in Acute Appendicitis in a Large Community Practice," The American Journal of Surgery, Vol. 195, No. 5, 2008, pp. 590-593.

[2] S. Bird, "Failure to Diagnose: Appendicitis," Australian Family Physician, Vol. 33, No. 12, 2004, pp. 1025-1026.

[3] E. K. Paulson, M. F. Kalady and T. N. Pappas, "Suspected Appendicitis," The New England Journal of Medicine, Vol. 348, No. 3, 2003, pp. 236-242. doi:10.1056/NEJMcp013351

[4] C. C. Liu, C. L. Lu, D. H. Yen, C. H. Chern, L. M. Wang and C. H. Lee, "Diagnosis of Appendicitis in the ED: Comparison of Surgical and Nonsurgical Residents" American Journal of Emergency Medicine, Vol. 19, No. 2, 2001, pp. 109-112. doi:10.1053/ajem.2001.20006

[5] R. A. Rusnak, J. M. Borer and J. S. Fastow, "Misdiagnosis of Acute Appendicitis: Common Features Discovered in Cases after Litigation," American Journal of Emergency Medicine, Vol. 12, No. 4, 1994, pp. 397-402. doi:10.1016/0735-6757(94)90047-7

[6] F. K. Althoubaity, "Suspected Acute Appendicitis in female patients. Trends in Diagnosis in Emergency Department in a University Hospital in Western Region of Saudi Arabia," Saudi Medical Journal, Vol. 27, No. 11, 2006, pp. 1667-1673

[7] M. F. Ditillo, J. D. Dziura and R. Rabinovici, "Is It Safe to Delay Appendectomy in Adults with Acute Appendicitis?" Annals of Surgery, 2006, Vol. 244, No. 5, pp. 656-660. doi:10.1097/01.sla.0000231726.53487.dd

[8] L. Graff, J. Russell, J. Seashore, et al., "False-Negative and False-Positive Errors in Abdominal Pain Evaluation: Failure to Diagnose Acute Appendicitis and Unnecessary Surgery," Academic Emergency Medicine, Vol. 7, No. 11, 2000, pp. 1244-1255.

doi:10.1111/j.1553-2712.2000.tb00470.x

[9] M. Kraemer, C. Franke, C. Ohmann, Q. Yang and Acute Abdominal Pain Study Group, "Acute Appendicitis in Late Adulthood: Incidence, Presentation, and outcome. Results of a Prospective Multicenter Acute Abdominal Pain Study and a Review of the Literature," Langenbecks Archives of Surgery, Vol. 385, No. 7, 2000, pp. 470-481.

\section{doi:10.1007/s004230000165}

[10] V. A. Pittman-Waller, J. G. Myers, R. M. Stewart, D. L. Dent, C. P. Page, G. A. Gray, B. A. Pruitt Jr. and H. D. Root, "Appendicitis: Why So Complicated? Analysis of 5755 Consecutive Appendectomies," The American surgeon, Vol. 66, No. 6, 2000, pp. 548-554

[11] S. Eldar, E. Nash, E. Sabo, I. Matter, J. Kunin, J. G. Mogilner and J. Abrahamson, "Delay of Surgery in Acute Appendicitis," The American Journal of Surgery, 1997, Vol. 173, No. 3, pp. 194-198.

[12] A. S. Earley, J. P Pryor, P. K. Kim, J. H. Hedrick, J. E. Kurichi, A. C. Minogue, S. S. Sonnad, P. M. Reilly and C. W. Schwab, "An Acute Care Surgery Model Improves Outcomes in Patients with Appendicitis," Annals of Surgery, Vol. 244, No. 4, 2006, pp. 498-504.

[13] D. Yardeni, R. B. Hirschl, R. A. Drongowski, D. H. Teitelbaum, J. D. Geiger and A. G. Coran, "Delayed versus Immediate Surgery in Acute Appendicitis: Do We Need to Operate during the Night?" Journal of Pediatric Surgery, Vol. 39, No. 3, 2004, pp. 464-469. doi:10.1016/j.jpedsurg.2003.11.020

[14] C. Brigand, J. P. Steinmetz and S. Rohr, "The Usefulness of Scores in the Diagnosis of Appendicitis," Journal de Chirurgie, Vol. 146, No. 1, 2009, pp. 2-7. doi:10.1016/j.jchir.2009.08.001

[15] C. J. Schupp, V. Klingmüller, K. Strauch, M. Bahr, D. Zovko, T. Hannmann and S. Loff, "Typical Signs of Acute Appendicitis in Ultrasonography Mimicked by Other Diseases?" Pediatric Surgery International, Vol. 26, No. 7, 2010, pp. 697-702. doi:10.1007/s00383-010-2617-2

[16] O. Monneuse, S. Abdalla, F. Pilleul, V. Hervieu, L. Gruner, E. Tissot and X. Barth, "Pain as the Only Consistent Sign of Acute Appendicitis: Lack of Inflammatory Signs does Not Exclude the Diagnosis," World Journal of Surgery, Vol. 34, No. 2, 2010, pp. 210-215. doi:10.1007/s00268-009-0349-z

[17] Y. Pouget-Baudry, S. Mucci, E. Eyssartier, A. GuesdonPortes, P. L ada, C. Casa, J. P. Arnaud and A. Hamy, "The Use of the Alvarado Score in the Management of Right Lower Quadrant Abdominal Pain in the Adult," Journal of Visceral Surgery, Vol. 147, No. 2, 2010, pp. e40-e44. doi:10.1016/j.jviscsurg.2010.05.002

[18] B. Sanei, M. Mahmoodieh and M. Hosseinpour, "Evaluation of Validity of Alvarado Scoring System for Diagnosis of Acute Appendicitis," Pakistan Journal of Medical Sciences, Vol. 25, No. 2, 2009, pp. 298-301.

[19] M. Horzić, A. Salamon, M. Kopljar, M. Skupnjak, K. Cupurdija and D. Vanjak, "Analysis of Scores in Diagnosis of Acute Appendicitis in Women," Collegium Antropologicum, Vol. 29, No. 1, 2005, pp. 133-138.

[20] A. Mohamed and N. Bhat, "Acute Appendicitis Dilemma of Diagnosis and Management," Internet Journal of Surgery, Vol. 23, No. 2, 2010, pp. 1528-8242.

[21] C. H. Chung, C. P. Ng and K. K. Lai, "Delays by Patients, Emergency Physicians, and Surgeons in the Management of Acute Appendicitis: Retrospective Study," Hong Kong Medical Journal, Vol. 6, No. 3, 2000, pp. 254-259. 